\title{
Knowledge Portal for Exclusion Process Services
}

\author{
Krzysztof Hauke \\ Wroclaw University of Economics \\ Komandorska 118/120, \\ 53-345 Wrocław, Poland \\ Email: krzysztof.hauke@ue.wroc.pl
}

\author{
Mieczysław L. Owoc \\ Wroclaw University of Economics \\ Komandorska 118/120, \\ 53-345 Wrocław, Poland \\ Email: mieczyslaw.owoc@ue.wroc.pl
}

\author{
Maciej Pondel \\ Wroclaw University of Economics \\ Komandorska 118/120, \\ 53-345 Wrocław, Poland \\ Email: maciej.pondel@ue.wroc.pl
}

\begin{abstract}
Exclusion phenomenon in common understanding denotes processes in which some group of people or individuals are permanently blocked from resources (mostly considered as social exclusion). For sure such sort of phenomena is observed as unwanted not only from "outsiders" but also from local and global society point of view. The exclusion (and its antonym inclusion) phenomenon can be investigated including many aspects: starting from identifying exclusion as a process, multidimensional research in this area up to solutions available in the domain.

In order to be successful in overtaking this phenomenon groups and institution involved in this process should be supported by ICT solutions. The paper consists of five parts which gradually present context of the problem and proposed solutions. After short introduction concerning research background the discussed concept of exclusion processes is presented. In the main section real examples of exclusion processes are investigated which allows to define assumptions of knowledge portal architecture and some examples of performed services. It creates opportunities for formulation final conclusions about the necessity and usability the developed platform.
\end{abstract}

\section{INTRODUCTION}

Nowadays people, especially in the era of information society, know more and more about a man, groups and the whole nations, about their needs and levels of satisfaction of the human beings alone or of human associations. If so, natural tendency - present in democracy - to treat all citizens equally becomes very important. Any form of discrimination some group of people is against the democratic order and societies and governments try to counteract with this unwanted phenomenon.

The roots of the exclusion phenomena "discovering" (or better reflexion on human sense of equality and justice) can be found in the discourse in France in the mid 1970s (see: $\mathrm{N}$. Rawal review of social inclusion and exclusion - [11]). A bit later H. Silver (see: [1]) formulated three paradigms of social exclusion: solidarity (stressing social dimension of human interactions), specialization (discovering exclusion as a form of discrimination) and monopoly (interpreting exclusion as a consequence of the existing group monopolies). Anyway in older and later approaches to the phenomena research many aspects of social exclusion and inclusion were analysed.

In order to be successful, a problem of exclusion should be investigated, reasons of its occurrence should be discovered and solutions for inclusion should be proposed. According to EU policy the poverty and exclusion problems are very important and responses could be projects prepared in the Europe 2020 strategy (Societal challenges section in Horizon 2020 programme, see: [14]).

Two examples should be stressed as promising solutions in the discussed area:

- GSDRC - Applied Knowledge Services devoted to maintaining knowledge about exclusion phenomena (see: [12])

- Exclusion-Inclusion Suburbs - prepared for knowledge services essential in city environments (see: [13]).

In both cases presented solutions are limited to selected phases or areas of exclusion phenomena. Therefore lack of common platform developed for the whole community seems to be obvious.

The paper is managed as follows. In the next section theoretical background of the investigated phenomena is described including nature of exclusion and inclusion phenomena, reasons of its occurrence is discussed and multidimensional characteristics of investigation is stressed. An essence of knowledge portals developed for modern society is presented in the subsequent section with focus on society needs and functionality such portals, offered architectures and applications useful for different segments of the society. The most innovative part of the research is presented in the main section of the paper devoted to concepts of the knowledge portal addressed to exclusives covering: assumptions, architecture and examples of supported tasks. The paper ends conclusion remarks and future research.

\section{EXCLUSION PROCESSES AS RESEARCH CHALLENGES}

No doubts, exclusion as a phenomenon seems to be very important and difficult problems to solve in modern society. There are many contexts in which exclusionary processes can occur including different objects, or time- and territoryaspects. At least two approaches should be taken into account actors-oriented and capability-oriented.

In accordance of the first one the critical thing is: relationships between "actors" essential for the exclusion. It is very important in understanding the "exclusion" idea as a concept. According to R Saith: [2] "Social exclusion is a 
socially constructed concept, and can depend on an idea of what is considered "normal"'. So here crucial topic of understanding discussed phenomenon is definition of normality which, in turn, depends on standard living, hierarchy of values, assumed criteria of society organization and the like what finally can be identified with "actors".

On the other hand A.Sen (see: [3]) keeps that an essence of social exclusion relates to 'functionings' and 'capabilities' concepts. Functionings denotes things important in leading life (health, education, cultural life etc.) while capabilities concerns individual combination of different functionings specific for human-beings or some group of people. So, social exclusion relies on inability of achieve certain 'functionings' or difficulties with reaching the goals which leads to deprivation and poverty - unwanted states in of any society.

Multidimensional character of exclusion has been stressed by the following authors: De Haan [4], Bhalla and Lapeyre [6], Burchardt et. al. [5] and Fisher [7]. Potential dimensions cover the different aspects: un/employment, markets (so difficulties with access to goods and services), neglecting of political laws and social relationships. Therefore in research conducted in this domain all aspects of exclusion processes should be examined not only individually but also from more general point of view. There are many intersections between the mentioned dimensions, for example: unemployment has the strong impact on poverty, poverty in turn causes limited access to services and products available on a market in local and global range and so on.

From individual as well as from society point of views the mentioned manifestations of exclusion processes lead to segregation of many sorts, sense of social inequality and conflicts in broader perspectives. Monitoring and investigation of the discussed phenomenon need to be performed continuously and be supported by information and communication technologies or better by specialized knowledge portal(s).

The described phenomenon basically relates to social exclusion which should be separated from voluntary exclusion - see Barry [8]. Exclusion of this short is a specific one and not always is regarded as unwanted process. On the contrary, as intentionally prepared and performed activities cannot be integrated with social exclusion.

The process considered as the solution to neutralize exclusion effects is called social inclusion. The social inclusion can be defined as ..." a process of improving the terms on which people take part in society" - see World Bank definition [15]. In sociology social inclusion means the provision of certain rights to all individuals and groups in society, such as employment, adequate housing, health care, education and training, etc. - see Collins Dictionary [12]. Of course social inclusion - as the process of organizing social life - sometimes is problematic or even inequitable - see Hickey and du Toit [9]. The concept of 'adverse corporation' brings better results because of its implementation in particular contexts - see [9].
Social inclusion as the process of counteraction negative results of exclusion should be supported in many ways by information technologies. Social equality should be enforced by access to information and knowledge available in computer networks; M. Warschauer discussed many aspects of usability and consequences of technology and social inclusion intersection see [10]. In the next part importance of knowledge portals as natural source of information for modern society is presented.

\section{KNOWLEDGE PORTAL FOR THE MODERN SOCIETY}

Portal - a website presenting the overview and systematic form the most important and best - developed articles, as well as other content related to the topic. It presents readers with the resources available on the subject in a more accessible and attractive than categories, indirectly encouraging the active involvement in the development of the content.

Web Portal (or Internet Portal) - an online information services extended to a variety of Internet functions, available from a single Internet address (compare [17]). Typically, the portal contains information of interest to a wide audience. As an example, you can specify the content of the portal: forum news, weather, web directory, chat, forums and mechanisms for information retrieval in the same or in external Internet sites (search engines). In addition, portals may offer free services such as email, web hosting.

Knowledge Portal (our interpretation) - an online service that includes a generally reliable information about a specific fragment of reality and can be used in the further development of the issues or bind it with another issue. Knowledge expressed in many forms including its own theories is a crucial component of the discussed portals. The classic approach takes into account the following elements:

- beliefs, judgments logically,

- justification belief is justified,

- veracity, the belief is true.

Examples of category knowledge portals:

- social sciences and humanities, such as astronomy, biology, chemistry, genetics, medical science, zoology,

- society, such as: anarchism, atheism, bible, biographies, philately, Hinduism, Judaism, Catholicism, the saints, the religious,

- geography, for example: individual continents, different countries, different cities,

- national, for example, Poland, Germany, USA,

- culture - fiction, film, comics, art, games, anime,

- $\quad$ sports, for example, the Olympic Games, check, ski jumping, rallies,

- technique, such as: architecture, electronics, energy, computers, mobile phones, websites, army,

- social sciences and humanities, such as philosophy, history, psychology, sociology, foreign languages,

The intentions of the portal is to encourage users to set the address as the portal home page in a Web browser, and treat 
it as a gateway to the Internet. There is a tendency as a synonym for the treatment of portal website.

One of the oldest knowledge portals is presented in Fig. 1 (see: [19]). Main functionality of the portal concerns to cooperation with experts, e-learning offerings, Case Law Directory apart of typical FAQ (frequently asked questions) capabilities.

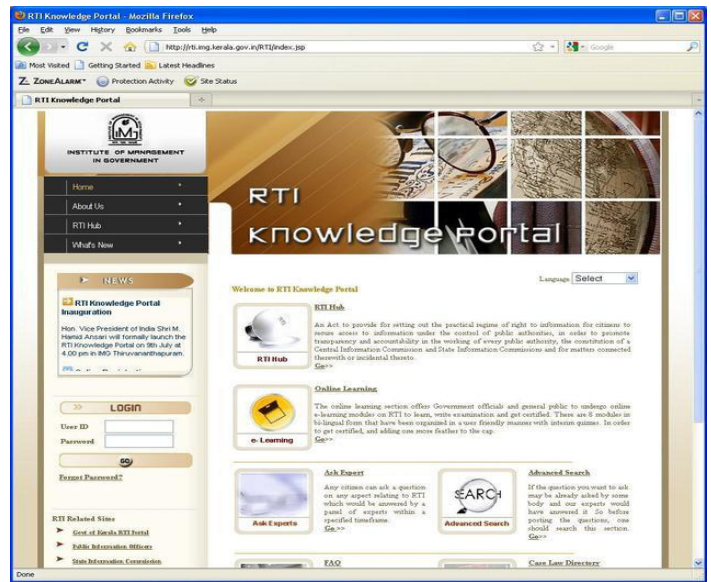

Fig. 1. An example of RTI Knowledge Portal

Another example of knowledge portal is depicted in Fig. 2 (available at [20]). The goal of its solution is to convince to company products as well as to offer complete courses devoted to accelerate user skills.

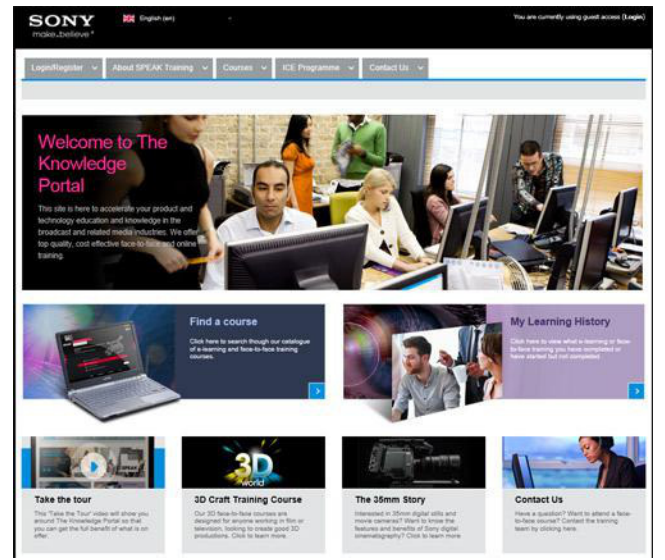

Fig. 2. Working with SONY Knowledge Portal

A useful tool for strengthening a network of people who are excluded can be a portal of knowledge. It serves not only as a tool to convey information, but above all to enrich and exchange their knowledge resources. Knowledge portal provides access to knowledge resources that are owned by all of the entities forming the network issues excluded people. The first impulse to gain specific knowledge resources is to determine your needs. Information goes to the portal, which locates the appropriate resource, a category of knowledge transfer process. Then the knowledge portal allows supplement domain knowledge. In this way, the knowledge portal becomes a compendium of knowledge on the particular matter. Site work requires not only knowledge of information technology, but appropriate organizational structure and knowledge management strategy. The proper functioning of the portal of knowledge brokers play an important role. They should be in the portals of knowledge as individuals or institutions performing oversight knowledge development in the portal. The main task of the broker is:

- assessment of the needs of the knowledge,

- location of resources,

- $\quad$ supervision of the transfer,

- assessment of the degree of absorption and utilization of knowledge.

All operators should be interested in the proper functioning of the portal of knowledge. Knowledge that remains in the resources the organization is the basis for the acquisition of new resources. We have in this case to deal with a spiral of knowledge that all time develops, through which actors are able to develop. Basic knowledge resources of the company are based on five categories of knowledge (compare [18]):

- codified knowledge,

- explicit knowledge,

- knowledge protected,

- tacit knowledge,

- latent knowledge.

The portal should provide exploration of tacit knowledge and latent. These two categories can contribute significantly to the development of the organization, and thus to achieve a competitive advantage. Portals should not only be sauce for the implementation of business functions typically associated with competitiveness, achieving measurable financial results. They should also be used for indirect actions that will achieve the objectives of a typical business. Different types of social organizations also need such solutions. A multitude of knowledge, which allows to solve problems of social institutions requires her to organize and codify the first stage of creating the portal. The next step is to complement this knowledge different solutions at the local or individual. The establishment and operation of such a portal will allow institutions to function more efficiently to deal with the problems of excluded people. Perhaps those who are excluded will return to society. However, their efficiency and effectiveness will be determined only by which time after testing.

\section{A CONCEPT OF KNOWLEDGE PORTAL FOR EXCLUSIVES}

Considering development of dedicated knowledge portal at least the following aspects should be taken into account: purpose and audience, technology and tools useful for the creation and maintenance stages. Initially our proposal of the portal is expressed in two parts: assumptions and architecture. 


\section{Assumptions}

We assume the following groups of people are the target users of the proposed portal:

- Policy makers - represented by politicians and officials who are responsible for legal solutions, law creation and adjustments.

- Social workers employed in:

- Governmental / local governmental units.

- NGO's - Non-governmental organizations.

- Institutions interested or engaged in the exclusion problem like universities/ scientific organisations and their researchers, media and journalists,

- Independent entities who are interested in the exclusion problem

- Commercial enterprises who develop programs / solutions targeted to help excluded groups

By using another perspective we can divide the users into:

- Corporate users representing authority organisations

- Individuals representing basically themselves that consist of:

○ Authorities that should be verified

- Regular users

The main basis of the portal assume that every published content is available for all portal users. There will be no confidential matters stored in the portal so there is no need to build sophisticated information protection module.

No confidentiality assumption determines the simplicity of permissions model in the portal. The administrators of the portal will be able to configure it's modules and manage the permissions for every defined role, but there is no need to limit the access to the specific content.

We perceive that if we build a dedicated authentication module with separated credential management it will become a serious pain point for the users who will be forced to create and remember yet another user login and password. That is why we would like to integrate with as many as possible authentication providers that can exchange the data with the portal. Such approach will allow the users to use in our portal the same credentials as they are using in their enterprise systems or social solutions. Our portal will be integrated with:

- LDAP solutions,

- Facebook/ twitter / google accounts.

Our authorisation module architecture approach will allow organisational users to authenticate in our portal with the corporate login and password or even include the portal into the corporate SSO (single sign-on) solution. Individual users will be able to access the portal with the private facebook account and sign in automatically.

Of course we can use the mixed mode of authentication which means that corporate users can use also their private social accounts if their prefer or if the integration with the corporate LDAP will be impossible.

The corporate users of the portal should be verified by:

- Portal administrators,

- Organisation representatives.
In case of the individual users that should be verified - this task will be done by portal administrators.

One of the most important assumptions regards the functional offerings of the portal. It is not designed to work with specific excluded people and solve their particular problems. The main aim of the portal is to connect, enhance the interchange of ideas, knowledge and experience between the experts engaged in exclusion problem. It is designated to inspire all the stakeholders to solve the general problem of exclusion and provide them relevant information and knowledge. That is why the portal will not consist workflow functionality/ application processing capabilities but it is focused on information and knowledge tools processing, ideas management, communication platform and e-learning modules.

\section{Architecture}

We propose the portal to be built in traditional three layers architecture presented in Fig. 3:

- Database layer - built as a database storing the business and process objects. In this layer all documents, multimedia files, learning objects that has no relational structure will be stored. This layer will also provide the services of reporting and integration with other systems.

Database layer will be supported also with Knowledge Base. The knowledge to the Knowledge Base will be supplied by:

- Experts (portal users)

- Knowledge exploration module that will be operated by portal power users with data exploration skills.

- Application layer that will be responsible for whole business logic. It will provide:

○ the basic portal functionality,

○ the communication services that will give the users possibility for on-line bilateral communication, teleconference services, offline communication,

- e-learning services with all capabilities for hosting and providing on-line courses,

- Presentation layer built in portal technologies (which means that all the portal features will be accessible by web browser). We must take into account that for some users the portal will not be a tool in which they will work every day. That is why from user perspective it is crucial to provide them notifications of all important event happening in portal as new available content, tasks for users, activities expected to be done by users and others. Such notifications will be provided by:

○ Automatically generated emails,

- Mobile application push notifications,

- Newsfeed published by social portal as Twitter or Facebook. 


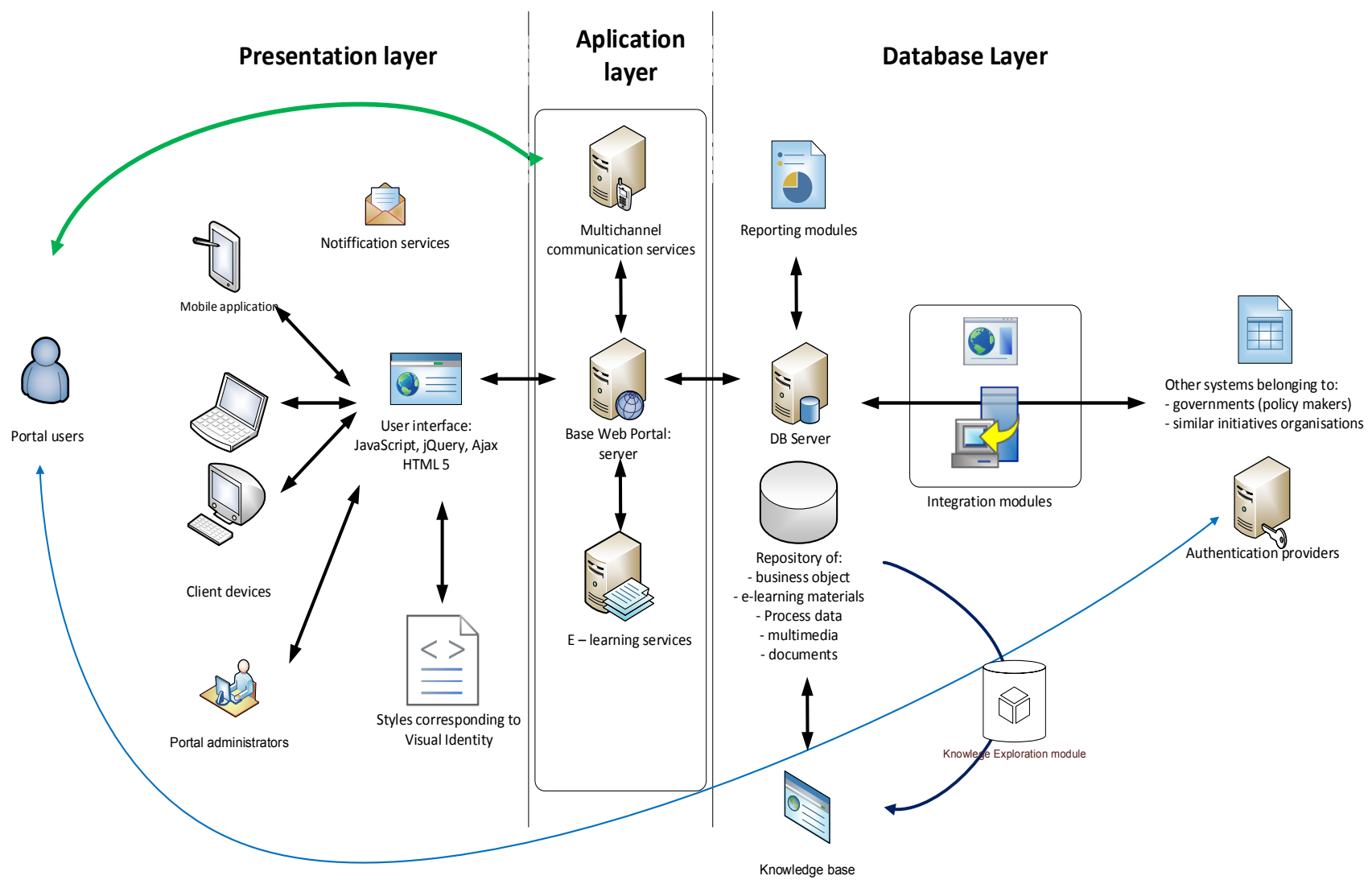

Fig. 3. Architecture of Knowledge Portal for Exclusives

Presentation layer will provide end users access to the information and knowledge stored in the database layer with regard to: users permissions and users preferences (content should be targeted to end user's needs and requirements).

\section{CONCLUSIONS AND FURTHER RESEARCH}

One of the most important problems of the modern society at the local, national and global levels is exclusion processes. The next findings can be formulated from the research:

- phenomena exclusion and inclusion in society are complex and multidimensional. Therefore investigation of such processes is difficult also because of differentiation of components, approaches and dimensions,

- information and communication technologies must support all processes belonging to registration and all services typical for exclusion and inclusion phenomena in modern society,

- the best solution for the discussed problems is specialized knowledge portal - proposed in the paper as a form of an initial version. At the beginning architecture will be developed for some narrow application and systematically extended covering new areas and levels of supporting.
Further investigations can be devoted to more deeply analysis of the problem in order to fulfill requirements of knowledge portal users. For example specification of knowledge bases and courses essential at local and/national level of administration.

\section{REFERENCES}

[1] Silver, H., 1994, "Social Exclusion and Social Solidarity: Three Paradigms", International Labour Review, Volume 133, Numbers 56, pp. 531-578.

[2] Saith, R., 2007, Social Exclusion: The Concept and Application to Developing Countries [in:] Stewart, F., Saith, R. and Harriss-White, B., (eds.), Defining Poverty in the Developing World, Palgrave, pp. 75-90.

[3] Sen, A., 2000, Social Exclusion: Concept, Application, and Scrutiny, Asian Development Bank.

[4] De Haan, A., 1999, Social Exclusion: Towards an Holistic Understanding of Deprivation, Department for International Development, London.

[5] Burchardt T., Le Grand J., and Piachaud D., 2002, Introduction, [in:] Hills, J., Le Grand, J. and Piachaud, D., Understanding Social Exclusion, Oxford University Press, Oxford.

[6] Bhalla, A. and Lapeyre, F., 1997, "Social Exclusion: Towards an Analytical and Operational Framework", Development and Change, Volume 28, pp. 413-433.

[7] Fischer, A., 2011, Reconceiving Social Exclusion, BWPI Working Paper 146, Brooks World Poverty Institute, Manchester.

[8] Barry, B., 1998, Social Exclusion, Social Isolation and Distribution of Income, Centre for Analysis of Social Exclusion, London School of Economics, London.

[9] Hickey, S. and du Toit, A., 2007, Adverse Incorporation, Social Exclusion and Chronic Poverty, Working Paper 81, Chronic Poverty Research Centre, University of Manchester. 
[10] Warschauer M., 2004, Technology and Social Inclusion. Rethinking the Digital Divide. The MIT Press, Massachusetts Institute of Technology.

[11] Rawal N., 2008, "Social Inclusion and Exclusion: A Review", Dhaulagiri Journal of Sociology and Anthropology Vol.2. pp. 161180.

[12] Social Exclusion portal: http://www.gsdrc.org/go/topic-guides/socialexclusion/definitions-and-different-understandings-of-socialexclusion [2014-04-23].

[13] Exclusion-Inclusion in Suburb: http:/www.hioa.no/eng/AboutHiOA/Centre-for-Welfare-and-Labour-Research/NOVA/NOVA-

Projects/Prosjekter-migrasjon-og-transnasjonalitet/Avsluttedeprosjekter/2011/Exclusion-and-inclusion-in-the-suburb/ (language)/eng-GB [2014-04-23].
[14] H2020 sections: http://ec.europa.eu/programmes/horizon2020/en/ h2020-sections [2014-04-23].

[15] World Bank website: http://www.worldbank.org/en/topic socialdevelopment/brief/social-inclusion [2014-04-23].

[16] Collins Dictionary website: http://www.collinsdictionary.com/ dictionary/english/social-inclusion [2014-04-23].

[17] Internet portal http://en.wikipedia.org/wiki/Internet_portal [2014-0423

[18] Knowledge concept http://en.wikipedia.org/wiki/Knowledge [201404-23].

[19] RTI Knowledge Portal http://rti.img.kerala.gov.in/RTI/index.jsp [2014-04-23].

[20] Sony Knowledge Portal https://training.sony-europe.com/ [2014-04-23]. 